\title{
APPLICATION OF INTERPRETIVE STRUCTURAL MODELING ON VERBAL AND NON-VERBAL COMMUNICATION MODELS BETWEEN LEARNING COMPANION HUMANOIDS AND ELDERLY HUMANS
}

\author{
Nor AyubtMeor Ahmad ${ }^{\mathrm{a}}$, Prof.SaedahSiraj ${ }^{\mathrm{b}}$ \\ ab University of Malaya, Kuala Lumpur, Malaysia \\ Corresponding email: ayumeor@siswa.um.edu.my
}

\begin{abstract}
As the number of elderly people in Malaysia increases, they might feel lonely as caregivers struggle to give care and provide companionship to the elders. Loneliness can lead to mental diseases like depression and dementia and that can have a negative impact on the quality of life of both elderly people and their caregivers. Therefore, a solution to overcome this problem is by using humanoids as companions for the elders and to encourage them to gain knowledge at a later age. This study aimed to develop a model on verbal and non-verbal communication between learning companion humanoids and elderly humans.

The model was produced by using Interpretive Structural Modeling (ISM) with the aid of Concept Star software that utilizes expert opinions. This method resulted in a total of 32 elements for the model and shows the relationships between them. Each element was further classified into four clusters which are Autonomous elements, linkage elements, dependent elements and independent elements, in terms of their driving and dependence powers through MICMAC analysis. This paper contributes to the Education and Artificial Intelligence fields by identifying the elements for effective verbal and non-verbal communication between humanoids and elderly humans and prioritizing them. The model will act as a guideline for successful communications between lonely elders, healthy elders and humanoids.
\end{abstract}

Keywords: Communication, Companionship, Elderly, Humanoids \& Interpretive Structural Modeling.

\section{Introduction}

In the year 2030, Malaysia is expected to become an ageing nation in which $15 \%$ of the population will be 60 years and above (Goh et al., 2013). This increase will lead Malaysia to become an ageing population in 2021 when the population aged 65 years and above reach 7.1 percent due to fertility decline and increased longevity (Department of Statistics Malaysia Official Portal, 2010). These statistics show that there will be more elderly people in Malaysia, as is happening in the rest of the world as well. With this increase, a few questions and problems will arise. Will the elderly be well taken care of? Will they be physically, mentally and emotionally healthy as the years go by? What will happen if they are not? Are we ready to care for the elderly and are we ourselves ready for our golden years? These questions just represent a few areas that we need to address to tackle the issues surrounding the ageing population.

\section{Research Problem}

As humans get older, we depend more on others(Johnson, et al., 2014). Most of us get weaker mentally and physically. The solution that we have today for the seniors is through the use of informal and formal caregivers. Informal caregivers are usually family members, relatives or 
even neighbours and friends who care for the elderly without profit. Formal caregivers are senior centres or old age homes where the seniors pay to get care. These current solutions are being overwhelmed by the increasing number of elderly and also the stress of caregiving (Lindgren et al., 2008).

However, our healthcare policies are getting better and people are also taking better care of themselves as they are getting more health-conscious. These factors contribute to the increased longevity and number of elders. These elders have a sense of independence and feel that they do not want to burden anyone while they can still care for themselves (Lai, 2009). The independent elders may have lost a spouse or have never been married. They may not have children, close relatives or friends that they can depend on without feeling guilty of being a burden. Some of them just refuse to live with others due to pride or ego and even because of their love for their home which can have sentimental value to them.

As the elders opt to stay alone rather than living with a caregiver, they are more prone to loneliness. With ageing, it gets harder to maintain relationships and they feel a loss of connection with the outside world. Loneliness is a dangerous thing as it can lead to a lot of mental diseases like depression and dementia that can cause various psychiatric and behavioural disturbances such as hallucinations, aggression and wandering (Smith, 2012). Such disorders have a negative impact on the quality of life of both elderly people and even their caregivers (Shibata \& Wada, 2010).

Animals or pets can be good companions, but they require energy, care and expenses that the elderly might not have. Some animals have fur or dander which might be detrimental to the elderly in terms of health and cleanliness. Allergies that they have may lead to serious health problems and caring for a sick pet is also not easy and sickness is bound to happen (Shibata and Wada, 2010). Going to the veterinarian is another hassle if the elder has problem with transportation. If the pet that they have is big or heavy, carrying the animal may harm the owner by breaking the owner's back. As the animals can move on their own accord and can be small, the seniors may trip on their pets while they are curled up on the floor or running around the place. Verbal communication will also be one-way as animals and humans do not share the same language.

In Malaysia, there is not enough support for lonely elders to achieve successful ageing. Therefore, alternative solutions are being sought to overcome this problem. One of the solutions is by using artificial intelligence or robots to aid humans in caring for the elderly (Morin et al., 2012). Quite a number of research projects pertaining to robots cater to the physical aspects of what a robot can do (Louie et al., 2014; Montemerlo et al., 2002; Fischinger et al., 2016), a handful cater to the needs of the elderly (Torta et al., 2014; Mitzner et al., 2014; Harmo et al., 2005) and an even smaller number focus on the verbal communication between elderly humans and robots (Yorita\& Kubota, 2011; Sugiyama et al., 2005). In Malaysia, I have found no local literature on verbal and non-verbal communication between robots and elderly humans.

\section{Concept of Communication}

Communication comes in verbal and non-verbal form. The verbal form includes the sounds, words, language and speaking style (Kim et al., 2013) that we use to convey information. Nonverbal communication consists of several categories like facial expressions, gaze, proxemics, paralanguage, etc. (Kleckova, 2009). It is mostly used to express our emotions. 
Humanoid communication is being researched on making it capable of intuitive multimodal communication with people (Bennewitz et al., 2007). It would enable the humanoids to be more efficient when communicating with humans and includes the use of multiple modalities like speech, facial expressions, gestures, body language, etc. As for communications between humanoids and the elders, the most important aspect for the elders is to gain a companion and a physical helper for difficult tasks (Zsiga et al., 2013). The humanoids should provide cognitive and physical support and also have perfect speech recognition and synthesis. As learning companions for the elderly, it is said that robotic conversation can activate the brain of the elderly and improve their concentration and memory (Yorita and Kubota, 2011). Consequently, the conversational capability of a humanoid is applied to the prevention of dementia and other mental diseases in the elderly.

\section{Interpretive Structural Modeling (ISM)}

ISM was first proposed by John N. Warfield (1976) to analyze a complex socioeconomic system. It is a well-recognized methodology for identifying relationships among specific items, which define a problem or an issue (Attri et al., 2013). It is computer-aided to develop a graphical representation of system composition and structure. ISM offers many advantages over other methods used for analysis and decision making (Lee, 1999). It addresses many communication problems associated with problem solving in a group environment like a lack of common language. In a group situation, the pair-wise analysis of ideas encourages contributions from people who understand the issues being discussed, but may not understand all issues related to the problem.

\section{Sample of Study}

The sample for this phase is a panel of heterogeneous experts carefully chosen for the purpose of the study. The same panel was used for the NGT process and ISM session as ISM is a continuation of NGT in this research study. The experts for both NGT and ISM sessions consist of two geriatricians, two experts in Artificial Intelligence, 3 experts in Communication and Language and one formal caregiver. This sums up to 8 experts in multiple fields. One of the experts, besides the formal caregiver, was a formal caregiver herself and a few experts are informal caregivers in which they take care of one elderly parent or both parents. Each of them has more than 5 years experience in their respective fields.

\section{Procedure of ISM}

\section{Identification of elements (NGT)}

In the development of the model,the first step is to identify the elements that are relevant to the issue. In order to do this, a modified nominal group technique (NGT) was used as it is more efficient and complementary to be paired with interpretive structural modeling (ISM). NGT is an established method to generate ideas or variables linking to an issue, problem or situation. Both of these techniques are similar in that they involve participants who have knowledge and interest about an issue (Kapelouzos, 2016). However, as NGT talks about the elements one-byone, ISM takes it a step further by using mathematical algorithm and the aid of a computer to organize the elements and their relationships into a structure. Therefore, the two techniques do complement each other.

In this study, instead of the experts generating ideas individually, they were given an initial list of elements that were compiled from literature review and interview of 5 experts. This helps to guide them in coming up with ideas related to the issue and it shortens the process of NGT to 
about an hour as the experts are very busy people and some of them had expressed their time constraints. In this list, the experts could choose to agree or disagree with the elements proposed and they could add other elements that they thought were relevant. Then, after the group discussion, a final list was given to each expert for them to give a ranking number to every element. The ranking was in a scale of one to seven where one indicates the least favourable and seven is the most favourable element to be included in the model. The ranking numbers given by the experts were added up to give priority values to each element. Finally, the NGT process ended with the elements being prioritized based on the priority values where the highest number would be the most important on the list. The elements are listed in Table 1 below. The numbering of the elements was also changed according to the priority values. For example, element 6 in NGT which is 'Body motion that is non-threatening to elders should be incorporated into the model e.g. slow movements, hand not raised too high' becomes element 1 inISM. 
Table 1: Ranking and Priority Values of Elements for NGT

\begin{tabular}{|c|c|c|c|c|c|c|c|c|c|c|c|}
\hline & Elements & EP1 & EP2 & EP3 & EP4 & EP5 & EP6 & EP7 & EP8 & Total & Priority \\
\hline 1 & The humanoid should have a female voice. & 5 & 6 & 7 & 6 & 4 & 7 & 6 & 5 & 46 & 14 \\
\hline 2 & The humanoid should have a male voice. & 3 & 6 & 4 & 2 & 4 & 4 & 2 & 5 & 30 & 32 \\
\hline 3 & The humanoid should start communication with the elders first. & 5 & 7 & 7 & 6 & 2 & 6 & 1 & 6 & 40 & 23 \\
\hline 4 & Elders should start communication with the humanoid first. & 5 & 4 & 5 & 2 & 5 & 5 & 7 & 1 & 34 & 28 \\
\hline 5 & $\begin{array}{l}\text { Comfortable distance and orientation between elders and } \\
\text { humanoids should be incorporated into the model. }\end{array}$ & 5 & 7 & 7 & 6 & 6 & 6 & 7 & 4 & 48 & 10 \\
\hline 6 & $\begin{array}{l}\text { Body motion that is non-threatening to elders should be } \\
\text { incorporated into the model e.g. slow movements, hand not } \\
\text { raised too high. }\end{array}$ & 7 & 7 & 7 & 7 & 7 & 7 & 7 & 5 & 54 & 1 \\
\hline 7 & The humanoid should have a moderate pitch of voice. & 3 & 6 & 7 & 6 & 7 & 7 & 7 & 6 & 49 & 9 \\
\hline 8 & The humanoid should have a friendly tone of voice. & 5 & 7 & 7 & 6 & 7 & 7 & 7 & 7 & 53 & 2 \\
\hline 9 & The humanoid should have a curious tone of voice. & 3 & 7 & 6 & 5 & 5 & 4 & 2 & 5 & 37 & 25 \\
\hline 10 & The humanoid should have an empathetic tone of voice. & 4 & 6 & 7 & 6 & 7 & 5 & 6 & 3 & 44 & 17 \\
\hline 11 & $\begin{array}{l}\text { The humanoid should have a happy or encouraging tone of } \\
\text { voice. }\end{array}$ & 6 & 7 & 7 & 6 & 7 & 5 & 7 & 6 & 51 & 6 \\
\hline 12 & The humanoid should have a slow rate of speech. & 5 & 5 & 5 & 5 & 2 & 5 & 2 & 3 & 32 & 29 \\
\hline 13 & The humanoid should have a moderate rate of speech. & 3 & 6 & 7 & 6 & 7 & 6 & 7 & 6 & 48 & 11 \\
\hline 14 & $\begin{array}{l}\text { Facts as verbal content such as medical content, television } \\
\text { programmes, and weather report should be incorporated into } \\
\text { the model. }\end{array}$ & 3 & 7 & 7 & 6 & 6 & 6 & 7 & 4 & 46 & 15 \\
\hline 15 & Jokes as verbal content should be incorporated into the model. & 2 & 7 & 7 & 3 & 3 & 6 & 7 & 4 & 39 & 24 \\
\hline 16 & $\begin{array}{l}\text { Inspirational quotes as verbal content should be incorporated } \\
\text { into the model. }\end{array}$ & 1 & 7 & 7 & 3 & 6 & 6 & 7 & 5 & 42 & 22 \\
\hline
\end{tabular}


Questions as verbal content such as "How are you?", "What do you mean?" and "Is it interesting?" should be incorporated into the model.

18 News as verbal content should be incorporated into the model. Responses as verbal content such as "Wow, that's amazing!",

19 "That's nice" and "Well done" should be incorporated into the model.

20 Humanoid should detect emotion of elders through tone of voice and respond accordingly.

If the elder does not respond to the humanoid, the humanoid

21 should wait for a response and prompt the elder until a response is heard.

22 If anger is detected from the elder, the humanoid should listen and respond accordingly.

If anger is detected from the elder, the humanoid should change the topic.

If sadness is detected from the elder, the humanoid should listen

24 and respond accordingly.

The humanoid should use a serious tone when reminding of

25 medication.

26 The humanoid should use a happy tone when reminding of

medication.

27 When anger is detected, the humanoid should use a happy tone.

28 When sadness is detected, the humanoid should use a happy tone.

29 When anger is detected, the humanoid should use a curious

tone.

30 When sadness is detected, the humanoid should use a curious

30 tone.

31 A neutral tone should be the default tone.

$\begin{array}{llllllllll}5 & 7 & 7 & 5 & 6 & 7 & 7 & 6 & 50 & 7 \\ 3 & 7 & 7 & 5 & 6 & 6 & 7 & 6 & 47 & 12 \\ 6 & 7 & 7 & 6 & 5 & 7 & 7 & 7 & 52 & 3 \\ 6 & 7 & 7 & 6 & 6 & 7 & 7 & 6 & 52 & 4 \\ 7 & 6 & 7 & 6 & 6 & 7 & 6 & 7 & 52 & 5 \\ 3 & 6 & 7 & 6 & 6 & 7 & 7 & 5 & 47 & 13 \\ 6 & 5 & 7 & 3 & 6 & 5 & 6 & 7 & 45 & 16 \\ 6 & 6 & 7 & 6 & 6 & 7 & 7 & 5 & 50 & 8 \\ 3 & 6 & 2 & 1 & 5 & 6 & 6 & 3 & 32 & 30 \\ 6 & 6 & 7 & 6 & 3 & 7 & 6 & 3 & 44 & 18 \\ 2 & 5 & 1 & 3 & 3 & 6 & 6 & 5 & 31 & 31 \\ 2 & 5 & 1 & 6 & 3 & 6 & 7 & 6 & 36 & 26 \\ 2 & 7 & 7 & 5 & 4 & 6 & 6 & 7 & 44 & 19 \\ 3 & 7 & 7 & 5 & 4 & 6 & 6 & 6 & 44 & 20 \\ 6 & 3 & 7 & 1 & 3 & 7 & 6 & 3 & 36 & 27\end{array}$




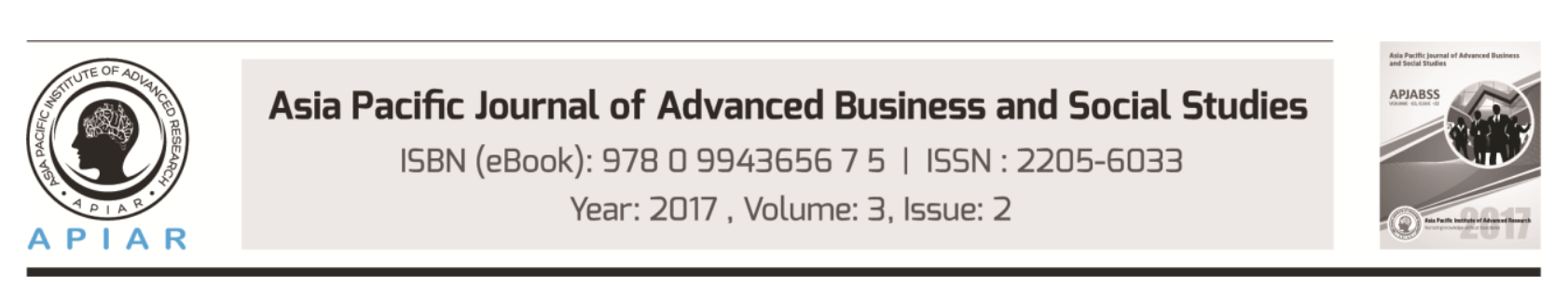

32 A happy tone should be the default tone. $\begin{array}{llllll}4 & 5 & 4 & 6 & 5 & 5\end{array}$ 43 Note: EP = Expert 


\section{Asia Pacific Journal of Advanced Business and Social Studies \\ ISBN (eBook): 9780994365675 | ISSN : 2205-6033 \\ Year: 2017, Volume: 3, Issue: 2}

\section{Contextual relationship phrase and relation phrase}

As the process of ISM starts, the contextual relationship and relation phrase for the elements should be determined. The contextual relationship refers to the objective or end result of this exercise. It provides the focus on how the elements need to be connected while constructing the ISM model. The relation phrase shows how the relationships between the elements are analyzed during ISM. The contextual relationship and relation phrase were determined by the consensus of the experts.

Based on the objectives of the study, the experts identified 'In order to promote effective companionship between learning companion humanoids and elderly humans' as the contextual relationship phrase and 'is more important than' as the relation phrase for the elements during the construction of SSIM. An example of a phrase that will be shown on the computer software is 'In order to promote effective companionship between learning companion humanoids and elderly humans, element ' $\mathrm{i}$ ' is more important than element ' $\mathrm{j}$ '.

\section{Development of the model}

A Structural Self-Interaction Matrix (SSIM) of the elements that shows the connection between them is then conducted with the aid of ISM software that was developed by Concept Star of Sorach Incorporation. The software displays the elements in pairs so that the experts can decide the relationship of the pairs through voting procedure. This process was repeated until all the elements were paired.

After the voting session and all the elements were successfully paired, the software generates the model based on the concept of pair wise comparison and transitive logic. Transitive logic states that for any 3 elements $(\mathrm{A}, \mathrm{B}, \mathrm{C})$ with a given relation:

- When $\mathrm{A}$ has a relation to $\mathrm{B}$ (written $\mathrm{A} \rightarrow \mathrm{B}$ ),

- And $\mathrm{B}$ has a relation to $\mathrm{C}$ (written $\mathrm{B} \rightarrow \mathrm{C}$ ),

- Then $\mathrm{A}$ has a relation to $\mathrm{C}$ (written $\mathrm{A} \rightarrow \mathrm{C}$ or $\mathrm{A} \rightarrow \mathrm{B} \rightarrow \mathrm{C}$ ).

The model is then shown to the experts to check for any conceptual inconsistencies or necessary modifications. The final model is shown in Figure 1. 

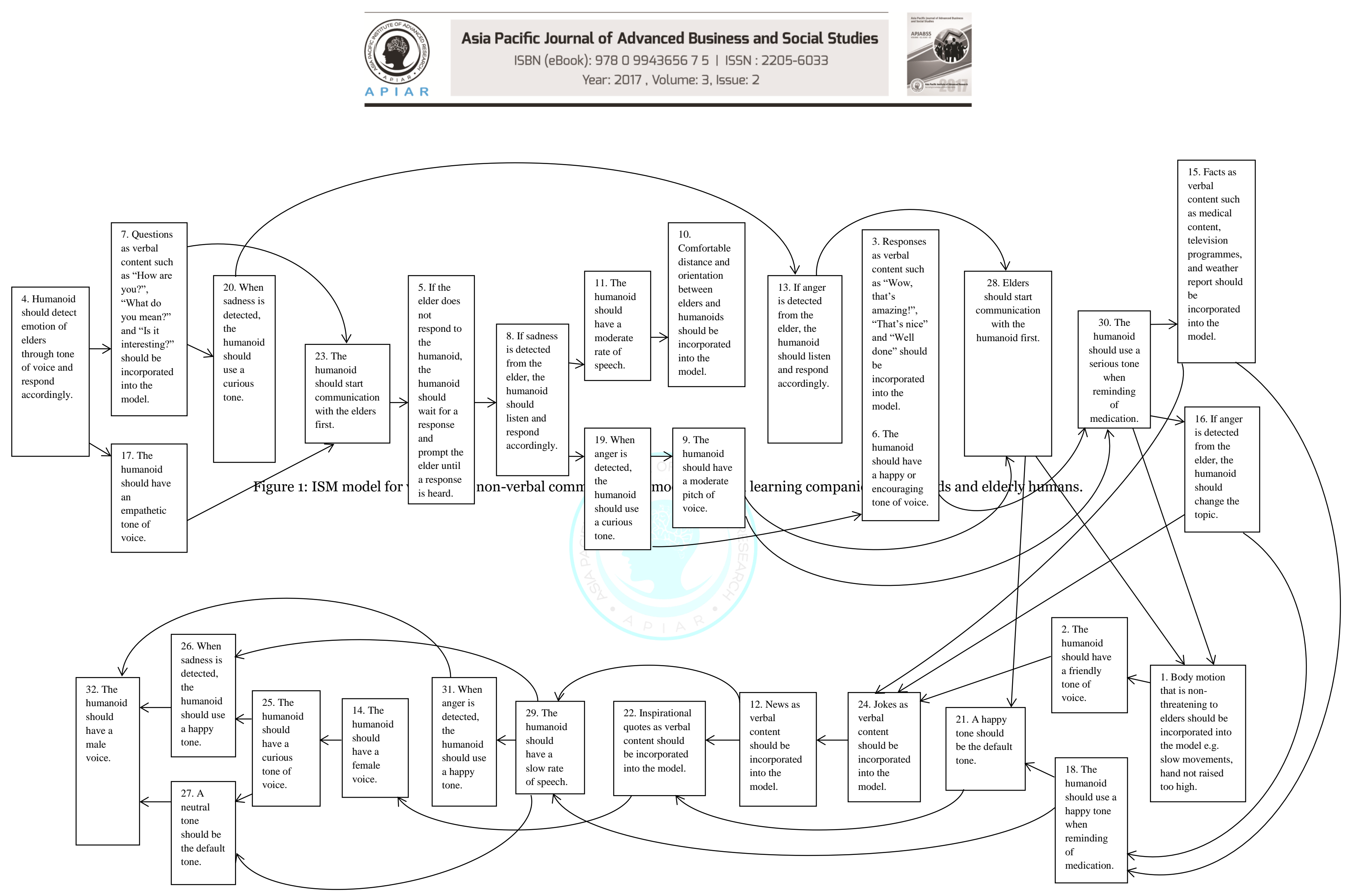


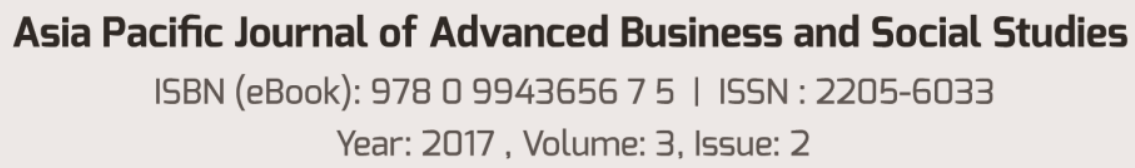

\section{Classification of elements based on the model}

As the model is generated, it has to be interpreted correctly in order to understand it. Therefore, the reachability matrix has to be partitioned to classify the elements into different levels. Generally, the matrix was achieved by substituting V, A, X and $\mathrm{O}$ to 1 and o based on the SSIM. The symbols V, A, X and $\mathrm{O}$ actually indicate the relationships between the pairs of elements: $\mathrm{V}$ - Element ' $\mathrm{i}$ ' influences element ' $\mathrm{j}$ '; $\mathrm{A}$ - Element ' $\mathrm{j}$ ' influences element ' $\mathrm{i}$ '; $\mathrm{X}$ Elements ' $i$ ' and ' $j$ ' influences each other; and $\mathrm{O}$ - Elements ' $\mathrm{i}$ ' and ' $\mathrm{j}$ ' are unrelated.

The substitution of the symbols with 1 s and os follow these conditions:If the (i, $j$ ) entry in SSIM is V, then (i, j) entry in the reachability matrix becomes 1 and the $(j, i)$ entry becomes $\mathrm{o}$; if the $(i, j)$ entry in SSIM is A, then $(i, j)$ entry in the reachability matrix becomes $o$ and the $(j, i)$ entry becomes 1 ; if the $(i, j)$ entry in SSIM is $X$, then $(i, j)$ entry in the matrix becomes 1 and the $(j, i)$ entry also becomes 1 ; if the (i, j) entry in SSIM is $O$, then (i, j) entry in the matrix becomes $\mathrm{o}$ and the $(\mathrm{j}, \mathrm{i})$ entry also becomes $\mathrm{o}$. Table 2 indicates the level partition of each element and it has already been incorporated into the final model in Figure 1.

Table 2: Level Partition of Reachability Matrix

\begin{tabular}{|c|c|c|}
\hline No & Elements & Level \\
\hline 32 & The humanoid should have a male voice. & 1 \\
\hline 26 & When sadness is detected, the humanoid should use a happy tone. & 2 \\
\hline 27 & A neutral tone should be the default tone. & 2 \\
\hline 25 & The humanoid should have a curious tone of voice. & 3 \\
\hline 14 & The humanoid should have a female voice. & 4 \\
\hline 31 & When anger is detected, the humanoid should use a happy tone. & 5 \\
\hline 29 & The humanoid should have a slow rate of speech. & 6 \\
\hline 22 & Inspirational quotes as verbal content should be incorporated into the model. & 7 \\
\hline 12 & News as verbal content should be incorporated into the model. & 8 \\
\hline 24 & Jokes as verbal content should be incorporated into the model. & 9 \\
\hline 21 & A happy tone should be the default tone. & 10 \\
\hline 2 & The humanoid should have a friendly tone of voice. & 11 \\
\hline 18 & The humanoid should use a happy tone when reminding of medication. & 11 \\
\hline 1 & $\begin{array}{l}\text { Body motion that is non-threatening to elders should be incorporated into the } \\
\text { model e.g. slow movements, hand not raised too high. }\end{array}$ & 12 \\
\hline 15 & $\begin{array}{l}\text { Facts as verbal content such as medical content, television programmes, and } \\
\text { weather report should be incorporated into the model. }\end{array}$ & 13 \\
\hline 16 & If anger is detected from the elder, the humanoid should change the topic. & 13 \\
\hline 30 & The humanoid should use a serious tone when reminding of medication. & 14 \\
\hline 28 & Elders should start communication with the humanoid first. & 15 \\
\hline 3 & $\begin{array}{l}\text { Responses as verbal content such as "Wow, that's amazing!", "That's nice" and } \\
\text { "Well done" should be incorporated into the model. }\end{array}$ & 16 \\
\hline 6 & The humanoid should have a happy or encouraging tone of voice. & 16 \\
\hline 13 & $\begin{array}{l}\text { If anger is detected from the elder, the humanoid should listen and respond } \\
\text { accordingly. }\end{array}$ & 17 \\
\hline 9 & The humanoid should have a moderate pitch of voice. & 18 \\
\hline 10 & $\begin{array}{l}\text { Comfortable distance and orientation between elders and humanoids should } \\
\text { be incorporated into the model. }\end{array}$ & 18 \\
\hline 11 & The humanoid should have a moderate rate of speech. & 19 \\
\hline 19 & When anger is detected, the humanoid should use a curious tone. & 19 \\
\hline 8 & $\begin{array}{l}\text { If sadness is detected from the elder, the humanoid should listen and respond } \\
\text { accordingly. }\end{array}$ & 20 \\
\hline 5 & $\begin{array}{l}\text { If the elder does not respond to the humanoid, the humanoid should wait for a } \\
\text { response and prompt the elder until a response is heard. }\end{array}$ & 21 \\
\hline
\end{tabular}




\section{Asia Pacific Journal of Advanced Business and Social Studies \\ ISBN (eBook): 9780994365675 | ISSN : 2205-6033 \\ Year: 2017, Volume: 3, Issue: 2}

23 The humanoid should start communication with the elders first.

22

20 When sadness is detected, the humanoid should use a curious tone.

23

7 Questions as verbal content such as "How are you?", "What do you mean?"

24 and "Is it interesting?" should be incorporated into the model.

17 The humanoid should have an empathetic tone of voice.

4 Humanoid should detect emotion of elders through tone of voice and respond

25 accordingly.

\section{Analysis and interpretation of model}

As the elements were put into different levels, with the highest number being the most important, they were also put into clusters according to their driving powers and dependency. This was further analysed using MICMAC (Cross-Impact Matrix Multiplication Applied to the Classification Analysis). It is usually used to classify the factors into four different categories (Tiwari, 2013), which are: Autonomous factors - they have weak drive power and weak dependence power. They are relatively disengaged from the system, but they have a few links, which may be very strong; dependent factors - they have weak drive power but strong dependence power; linkage factors - they have strong drive power and strong dependence power. These factors are unstable in the fact that any action on these factors will have an effect on others and also a feedback effect on themselves; and independent factors they have strong drive power but weak dependence power. Figure 2 shows the MICMAC analysis-matrix. 


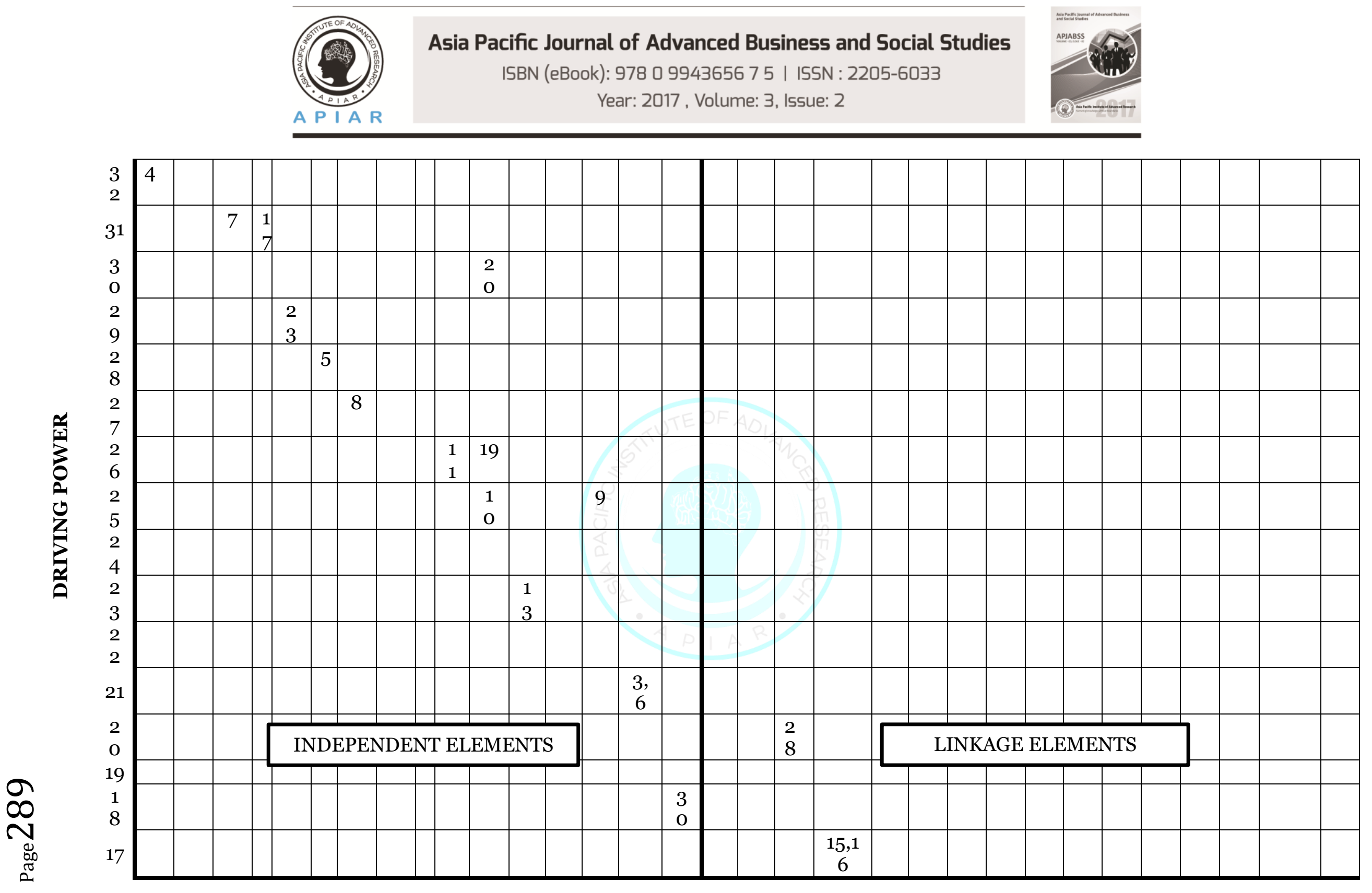




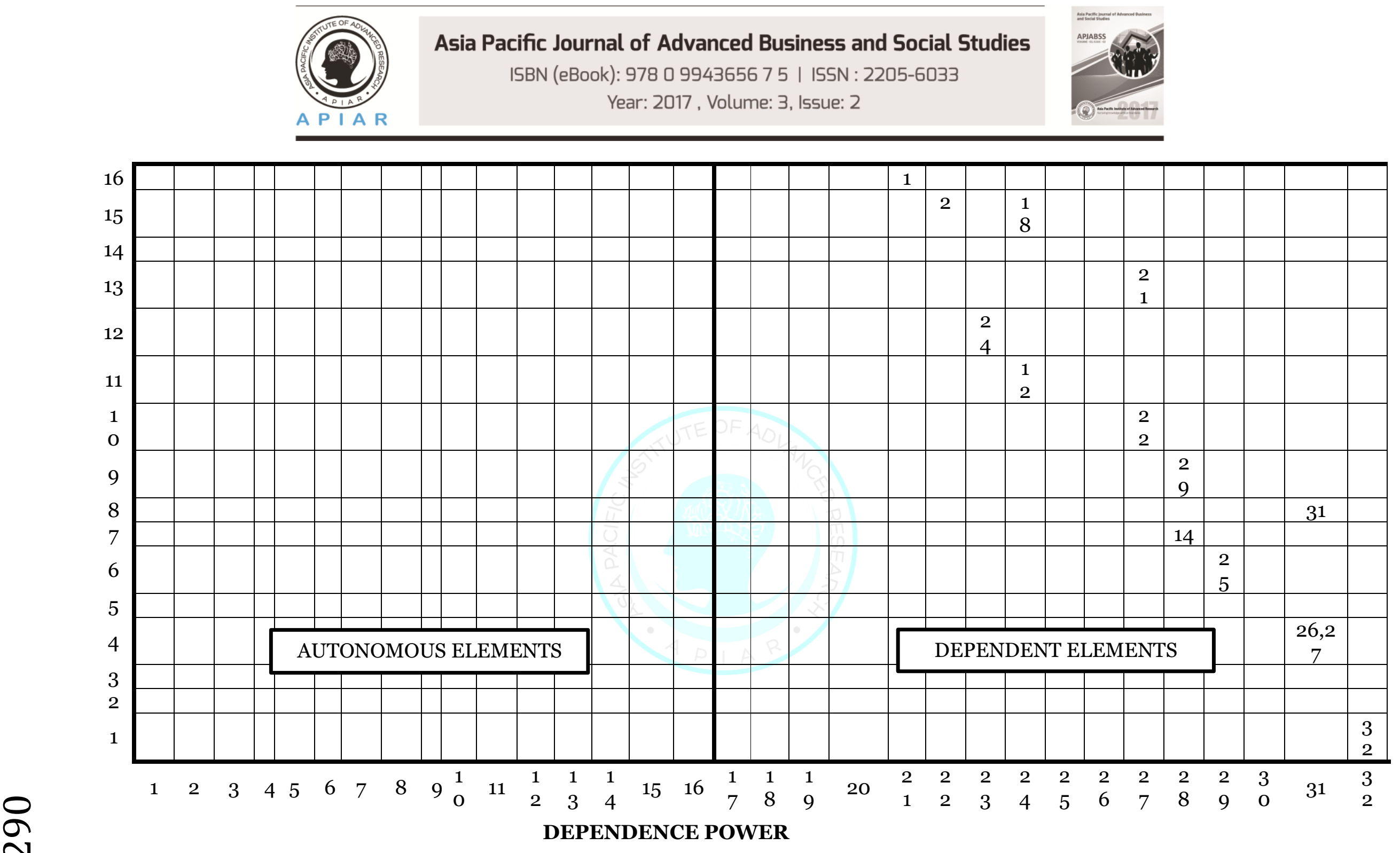

Figure 2: MICMAC analysis matrix for verbal and non-verbal communication model. 


\section{Asia Pacific Journal of Advanced Business and Social Studies \\ ISBN (eBook): 9780994365675 | ISSN : 2205-6033 \\ Year: 2017, Volume: 3, Issue: 2}

\section{Conclusion}

In the process of NGT, important elements for the verbal and non-verbal communication model between learning companion humanoids and elderly humans were narrowed down through literature and expert opinions from multiple fields. The elements are then put in order of importance mathematically through ISM and analysed on their driving powers and dependency through MICMAC analysis.

The ISM model shows that element 4, which is 'humanoid should detect emotion of elders through tone of voice and respond accordingly' is the most important element in the model and should be addressed first for communication between humanoids and the elderly. This is further validated through MICMAC as it is classified in the independent cluster with high driving power and low dependence on other elements. Elements that are on the same level like elements 7 and 17 are equally important and should be dealt with before proceeding to the elements in the next level but they do not influence each other. Elements 15, 16 and 28 in the linkage cluster play an important role in linking the upper elements (independent elements) to the lower elements in the model. As an example, element 28 depends on the finality of elements 3 and 6 and must be dealt with fully before proceeding because it affects element 1. Elements in the dependent cluster are influenced by other elements that they are linked to, as shown by the arrows in the model. Autonomous elements have no influence on the implementation of the model and fortunately, no elements fall under that cluster.

As a conclusion, the verbal and non-verbal communication model between learning companion humanoids and elderly humans is a very useful guideline for robot manufacturers to pay attention to for the future of our elders because it also affects the youth and the country. 


\section{References}

i. $\quad$ Attri, R., Dev, N. \& Sharma, V., 2013. Interpretive structural modelling (ISM) approach: An Overview. Research Journal of Management Sciences, 2(2), pp. 3-8.

ii. Bennewitz, M. et al., 2007. Fritz - A humanoid Communication Robot. New York: IEEE.

iii. Bolin, K., Lindgren, B. \& Lundborg, P., 2008. Informal and formal care among single-living elderly in Europe. Health Economics, 17(3), pp. 393-409.

iv. Cavallaro, F. et al., 2012. Growing Older together: when a robot becomes the best ally for aging well. s.l.:s.n.

v. Department of Statistics Malaysia, 2010. Official Portal. [Online] Available at: statistics.gov.my

vi. Fischinger, D. et al., 2016. Hobbit, a care robot supporting independent living at home:First prototype and lessons learned. Robotics and Autonomous Systems, Volume 75, pp. 60-78.

vii. Goh, Z., Lai, M., Lau, S. \& Ahmad, N., 2013. The Formal and Informal Long-Term Caregiving for the Elderly: The Malaysian Experience. Asian Social Science , 9(4), pp. 174-184.

viii. Harmo, P. et al., 2005. Needs and Solutions - Home Automation and Service Robots for the Elderly and Disabled., s.l.: s.n.

ix. Johnson, D. et al., 2014. Socially Assistive Robots: A Comprehensive Approach to Extending Independent Living. International Journal of Social Robotics,, 6(2), pp. 195-211.

x. Kapelouzos, I., 2016. The impact of structural modeling on the creation of new perspectives in problem-solving situations, s.l.: s.n.

xi. Kim, Y., Kwak, S. \& Kim, M., 2013. Am I acceptable to you? Effect of a robot's verbal language forms on people's social distance from robots.. Computers in Human Behavior, 29(3), pp. 1091-1101.

xii. Kleckova, J., 2009. Important Nonverbal Attributes for Spontaneous Speech Recognition, s.l.: s.n.

xiii. Lai, D., 2009. From Burden to Depressive Symptoms: The Case of Chinese-Canadian Family Caregivers for the Elderly. Social Work in Health care, 48(4), pp. 432-449.

xiv. $\quad$ Lee \& Donna, M., 1999. Structured Decision Making with Interpretive Structural Modeling (ISM): An analysis and decision-making method and tool for individuals and groups. Ontario: Sorach Inc.

xv. Louie, W., McColl, D. \& Nejat, G., 2014. Acceptance and Attitudes Toward a Human-like Socially Assistive Robot by Older Adults. Assistive Technology, 26(3), pp. 140-150.

xvi. Mitzner, T., Chen, T., Kemp, C. \& Rogers, W., 2014. Identifying the Potential for Robotics to Assist Older Adults in Different Living Environments. International Journal of Social Robotics, 6(2), pp. 213-227.

xvii. Montemerlo, M. et al., 2002. Experiences with a Mobile Robotic Guide for the Elderly. American Association for Artificial Intelligence Proceedings , pp. 587-592.

xviii. Shibata, T. \& Wada, K., 2010. Robot Therapy: A New Approach for Mental Healthcare of teh Elderly. Gerontology, Volume 57, pp. 378-386.

xix. Smith, J., 2012. Toward a Better Understanding of Loneliness In Community-Dwelling Older Adults. Journal of Psychology, 146(3), pp. 293-311. 


\section{Asia Pacific Journal of Advanced Business and Social Studies \\ ISBN (eBook): 9780994365675 | ISSN : 2205-6033 \\ Year: 2017, Volume: 3, Issue: 2}

xx. Sugiyama, O. et al., 2005. Three-layered draw-attention model for humanoid robots with gestures and verbal cues, s.l.: IEEE.

xxi. Tiwari, R., 2013. Identification of factors affecting reverse chain performance in relation to customer satisfaction using ISM Modelling \& MICMAC Analysis.. Uncertain Supply Chain Management , 1(4), pp. 237-252.

xxii. Torta, E. et al., 2014. Evaluation of a Small Socially-Assistive Humanoid Robot in Intelligent Homes for the Care of the Elderly. Journal of Intelligent and Robotic Systems , 76(1), pp. 5771.

xxiii. Yorita, A. \& Kubota, N., 2011. Cognitive Development in Partner Robots for Information Support to Elderly People. Ieee Transactions on Autonomous Mental development, 3(1), pp. 64-73.

xxiv. Zsiga, K. et al., 2013. Home care robot for socially supporting the elderly: focus group studies in three European countries to screen user attitudes and requirements. International Journal of Rehabilitation Research, 36(4), pp. 375-378. 